\title{
The Effect of Counter-face Roughness on the Tribological Behavior of Filled and Unfilled PTFE
}

\author{
Zeynep Parlar, Shahrad Samankan and Vedat Temiz \\ Mechanical Engineering Faculty, Department of Mechanical Engineering, Istanbul Technical University, Istanbul 34437, Turkey
}

\begin{abstract}
Since the wear problems play a crucial role in the relatively moving systems, in this paper, the effect of counter-face roughness on the wear of extruded PTFE (polytetrafluoroethylene) which is a very common material for sliding bearing applications has been investigated to contribute related literature. PTFE is well-known for its exceptional tribological properties, and good toughness, and high thermal stability. It can also be used in dry sliding applications. PTFE is commonly used to reduce friction between relatively moving surfaces. Its wear rate can be reduced by adding micro or nano-sized fillers such as $\mathrm{Al}_{2} \mathrm{O}_{3}, \mathrm{TiO}_{2}, \mathrm{SiO}_{2}$, $\mathrm{MoS}_{2}, \mathrm{Al}, \mathrm{Pb}, \mathrm{ZnO}, \mathrm{Cu}, \mathrm{ZrO}_{2}, \mathrm{Ni}, \mathrm{CNF}$ (carbon nano fiber), carbon fiber, glass fiber, bronze, and graphite powder into the PTFE. In this study, an experimental research was carried out for filled and unfilled PTFE to compare their behaviors under different speeds and loads. Test materials were unfilled PTFE, PTFE + wt. 5\% $\mathrm{Al}_{2} \mathrm{O}_{3}$, PTFE + wt. 15\% Al2O3. Formation of transfer film was examined in dry sliding condition against stainless steel counter faces. All tribological tests were carried out in a commercially available tribo-tester sliding against AISI-416 C stainless steel. As a result of a series of systematic experiments, remarkable results have been obtained to make a distinctive comparison between unfilled and filled PTFE. The variation of friction coefficient with sliding distance during the tests has also been recorded. At the end of the tests, wear rate of related PTFE specimen was calculated based on measured data. Wear rate is found very high for unfilled PTFE, however, the lowest wear rate is recorded for PTFE + wt. $15 \% \mathrm{Al}_{2} \mathrm{O}_{3}$ as expected. The coefficient of friction remained approximately stable during the wear tests. Transfer films were inspected by observing the discs' surface with optical microscope.
\end{abstract}

Key words: Wear, friction, $\mathrm{PTFE}, \mathrm{Al}_{2} \mathrm{O}_{3}$, surface roughness.

\section{Introduction}

In some applications, applying a third matter between relatively moving surfaces as lubricant cannot be possible due to operational or functional reasons. In such cases, a special material having favorable tribological properties under dry running conditions can be used. One of these materials is PTFE (polytetrafluoroethylene). PTFE polymer has a good toughness, low friction, and high thermal stability. This popular material can work in dry sliding applications and generally used in contacting surfaces and bearing applications $[1,2]$. Its low coefficient of friction is due to the high tendency of PTFE macromolecules to form a transfer film [3]. Despite the low friction coefficient, the wear characteristic of unfilled PTFE is very poor.

PTFE's unfavorable wear rate can be reduced about

Corresponding author: Zeynep Parlar, assist. prof., Ph.D., research fields: tribology and machine design. two or four orders of value by adding any micro or nano sized fillers such as $\mathrm{Al}_{2} \mathrm{O}_{3}$ [4], $\mathrm{ZnO}, \mathrm{MoS}_{2}, \mathrm{SiC}$, $\mathrm{SiO}_{2}, \mathrm{ZrO}_{2}, \mathrm{Al}, \mathrm{TiO}_{2}, \mathrm{Cu}, \mathrm{Pb}, \mathrm{Ni}, \mathrm{CNF}$ (carbon nano fiber), PEEK (polyetheretherketone), carbon fiber, glass fiber, bronze, and graphite powder into the PTFE [1]. The decrease in wear rate depends on various factors such as aspect ratio, type, size, shape, and crystal structure of the fillers, degree of dispersion of filler, and operating conditions $[5,6]$.

Some researchers have carried out experimental work on different additives of PTFE composite material, different surface roughness and sliding distance by changing the parameters. Sawyer et al. [4] investigated that the wear rate of PTFE nanocomposites decreases with increasing $\mathrm{Al}_{2} \mathrm{O}_{3}$ amount. The lowest wear rate is for $20 \%$ wt. $\mathrm{Al}_{2} \mathrm{O}_{3}$ polymer and it is about $1.2 \times 10^{-6}$ $\mathrm{mm}^{3} /$ N.m. However, it found that higher wear rate for unfilled PTFE is $740 \times 10^{-6} \mathrm{~mm}^{3} /$ N.m [7]. Stanković et 
al. [9] noticed that coefficient of friction generally remains in the range of 0.1 to 0.3 . When PTFE composites are compared with unfilled PTFE, the coefficient of friction decreases slightly in their composites used in experiments. However, they found that filler materials are of quite significant importance on the wear of filled PTFE. Their experiments showed that the best result about wear resistance obtained for PTFE + bronze filler composite which have been worked about 2,500 meter under $60 \mathrm{~N}$ load and speed of $1.5 \mathrm{~m} / \mathrm{s}$ showing no remarkable weight loss.

Filler material investigated in this paper is $\mathrm{Al}_{2} \mathrm{O}_{3}$ (Alumina). Tribological characteristics studied in this work are coefficient of friction and wear. In an investigation carried out by Mr. Dinghanxiang et al [10], unfilled PTFE had the highest wear loss when compared to PTFE $+15 \%$ alumina and PTFE $+20 \%$ alumina as expected. Same materials have been investigated as journal bearing by Parlar and Temiz [11].

There are many factors that affect polymer material's tribological properties. For polymer composites the most critical factors are [8]:

Normal load: A polymer composite functions as a solid lubricant if it is able to support the load, as well as the tangential stresses due to sliding. At light loads, typically low wear occurs, resulting from the local plastic flow of the thin transfer film and surface layers. However, at heavy loads severe wear occurs, caused by brittle fracture or plastic deformation.

Contact area: The contact area determines the magnitude of contact stresses. If the load cannot be reduced in order to reduce corresponding stress, the projected contact area should be increased.

Sliding speed: The high sliding speeds can generate high temperatures due to frictional heat. This may cause the polymer or the polymer composite fillers to deteriorate. On the other hand, in some cases higher temperature could be useful for lubricating process.

Surface roughness: One of the most important factors which affect tribological characteristic, is the surface roughness of counter faces. It could be generally accepted that, the counterpart with smoother surface have the lower wear rate [9]. In order to explain surface roughness, many roughness parameters are available for characterization. Further, the most common surface roughness parameter to characterize a surface is $\mathrm{Ra}$ (average surface roughness) $[9,12]$. The coefficient of friction does not change more with surface roughness (as given by $\mathrm{Ra}$ ) in the P. L. Menezes et al.'s work's test range. However, it is demonstrated that it depends on surface texture [12].

Temperature: At lower temperatures, the friction and wear properties of most polymers are not as exceptional as they are at or above the ambient temperature [9].

In this work, the effect of surface roughness on the friction and wear characteristics of unfilled and filled PTFE has been investigated experimentally. The variation of friction coefficient with sliding speed has been determined for PTFE specimens sliding against two different counter-faces having different surface roughness values. The wear rate has been determined based on results obtained from the frictional experiments.

\section{Experimental Study}

\subsection{Materials}

AISI $416 \mathrm{C}$ stainless steel was used as a disc (counter face) material having hardness of $52 \mathrm{HRC}$. The disc has a thickness of $16 \mathrm{~mm}$ and a diameter of $60 \mathrm{~mm}$. The surface roughness of the disc was measured using Perthometer S2 (Mahr Federal Inc., Providence, RI, USA), which gives the average deviation of the mean height of the entire surface within the sampling length. The cut-off length and the traversing length were set at $0.8 \mathrm{~mm}$ and $10 \mathrm{~mm}$, respectively. The mean surface roughness $(\mathrm{Ra})$ is the arithmetic mean of the absolute values of the heights between the actual and mean profiles. The calculation process for Ra value was achieved automatically by the processor of the Perthometer S2 regarding the surface profiles and was given numerically in micron meters. For accuracy, the mean surface roughness $(\mathrm{Ra})$ values of each disc were 
measured in axial and circumferential direction as shown in Fig. 1. The measurements were repeated five times at a different location for both directions in order to obtain the general surface characteristics of discs. The result of measurements is shown in Table1.

Polymer specimens are cylindrical pins with $10 \mathrm{~mm}$ diameter and $12 \mathrm{~mm}$ length. Sliding surface of the pins were formed in the same radius of the discs $(R=30$ $\mathrm{mm})$. Unfilled PTFE and PTFE with filled 5\% wt and $15 \%$ wt, $\mathrm{AL}_{2} \mathrm{O}_{3}$ were used in this study.

\subsection{Test Setup}

A commercially available block-on-ring apparatus was used to determine the friction and wear properties of test specimens. The principle of experimental setup is given schematically in Fig. 2. As shown in Fig. 2, normal load acting on the stationary test specimen was applied through the load holder by using dead-weights. The friction force occurred between the test specimen and the disc during sliding motion was measured by a force transducer placed on the pin holder. The force

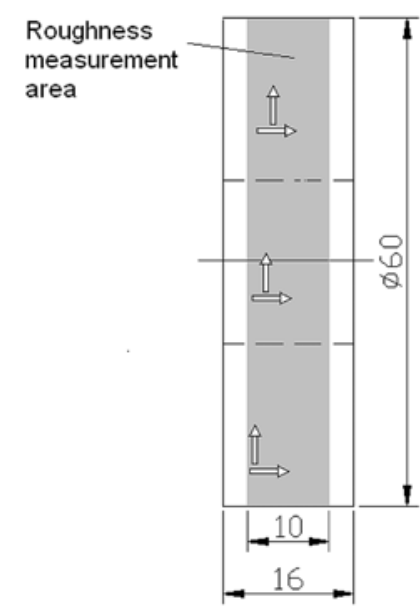

Fig. 1 Surface roughness measurement area of discs.

Table 1 Average of surfaces Ra.

\begin{tabular}{ll}
\hline & Ra $(\boldsymbol{\mu m})$ \\
\hline Disc 1 & 0.12 \\
Disc 2 & 0.71 \\
Disc 3 & 1.14 \\
Disc 4 & 1.53 \\
Disc 5 & 2.17 \\
Disc 6 & 2.97 \\
\hline
\end{tabular}

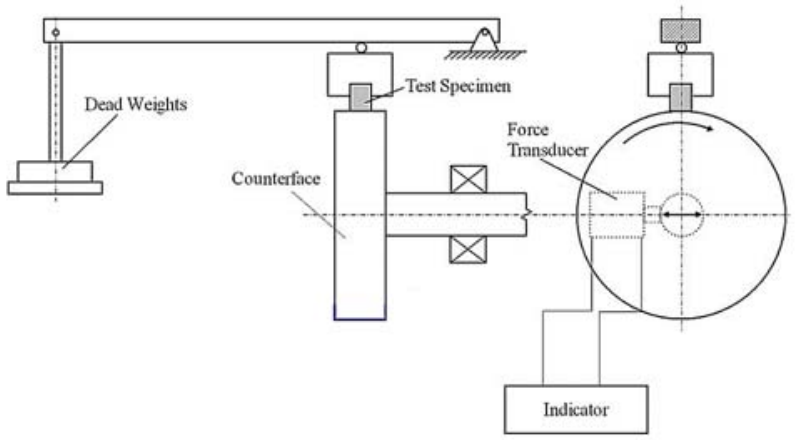

Fig. 2 The schematic view of experimental setup.

transducer has a load range of $\pm 200 \mathrm{~N}$ with a sensitivity of $\pm 2 \mathrm{mV}$, which is equivalent to a maximum $\pm 0.1 \mathrm{~N}$ error in the measurements. The counter-face (disc) was driven by a D.C. Motor in 30-800 rpm (0.1-2.5 m/s) variable speed range. The wear experiments were carried out on the basis of loss of mass measured with a scale having 0.0001 gr in accuracy.

\subsection{Test Procedure}

The experiments were carried out in $18-20{ }^{\circ} \mathrm{C}$ environment and $40-50 \%$ relative humidity. Before each test, both disc and pin specimen surfaces were cleaned with carbon tetrachloride to eliminate the detrimental effect of residual debris from earlier experiments. During the tests, a control panel was used to control the sliding speed (rpm) and the number of revolutions is counted for specified sliding distance. The friction tests were performed at ten different sliding speeds between 0.2 and $2 \mathrm{~m} / \mathrm{s}$ and three different normal loads 50, 100 and $150 \mathrm{~N}$. For wear tests, the constant normal load and sliding speed were selected as $100 \mathrm{~N}$ and $0.6 \mathrm{~m} / \mathrm{s}$, respectively. The sliding distance was set at $200 \mathrm{~m}$. During the wear tests, the coefficient of friction with respect to sliding distance was also recorded. After the wear tests, the disc surfaces were investigated by optical microscope.

The specific wear rate $(\mathrm{k})$ of the filled and unfilled PTFE pins was calculated by Eq. (1):

$$
k=\frac{\Delta m}{F \cdot L}
$$

where, $\Delta m$ is the loss of mass ( $\mathrm{g}), F$ is the normal load $(\mathrm{N})$, and $L$ is the sliding distance $(\mathrm{m})$. 


\section{Results and Discussion}

The variations of friction coefficient with respect to sliding speed for unfilled, $5 \% \mathrm{Al}_{2} \mathrm{O}_{3}$ filled, and $15 \%$ $\mathrm{Al}_{2} \mathrm{O}_{3}$ filled PTFE sliding against six discs having different surface roughness values are shown in Figs. $3-5$, respectively. In general, it can be concluded that friction coefficients increase with increasing sliding

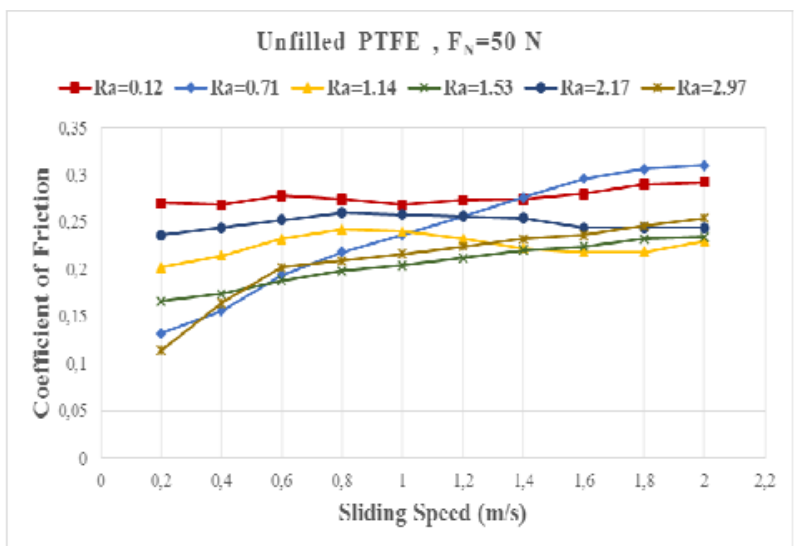

(a)

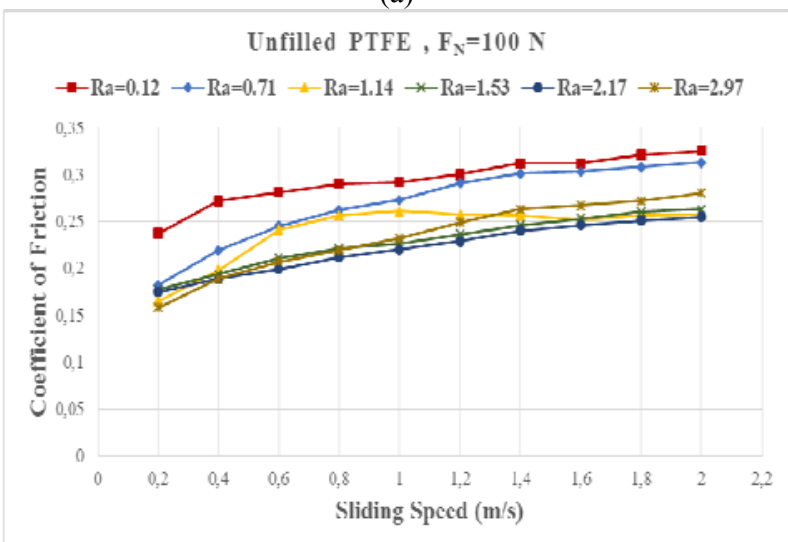

(b)

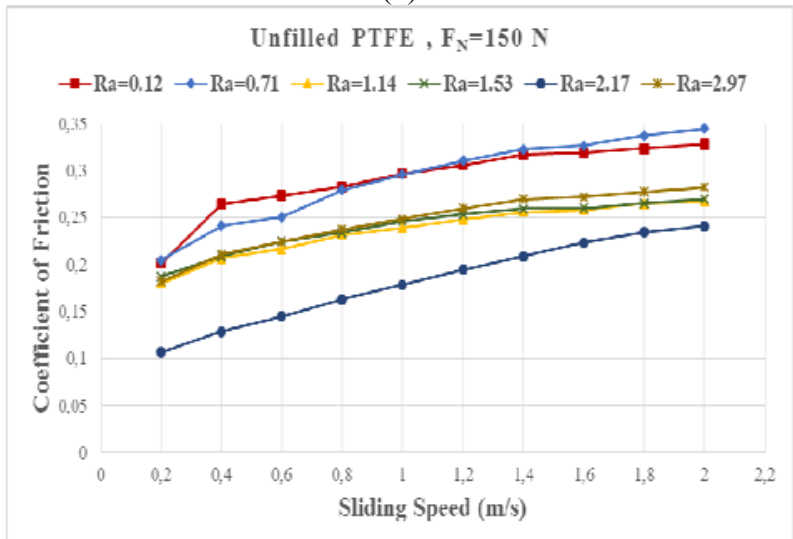

(c)

Fig. 3 Variation of coefficient friction with sliding speed for unfilled PTFE.

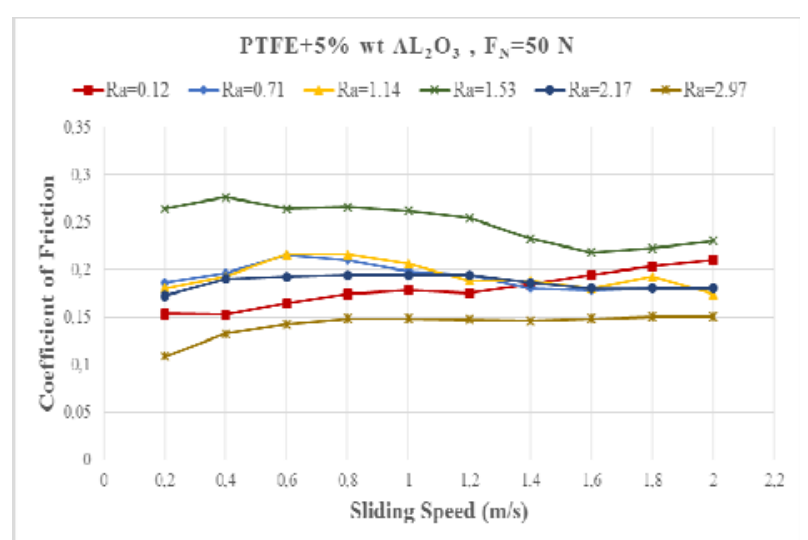

(a)

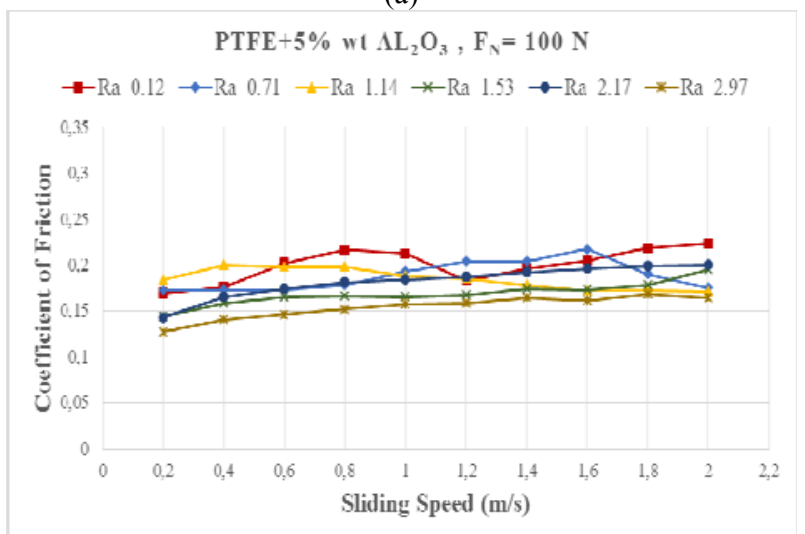

(b)

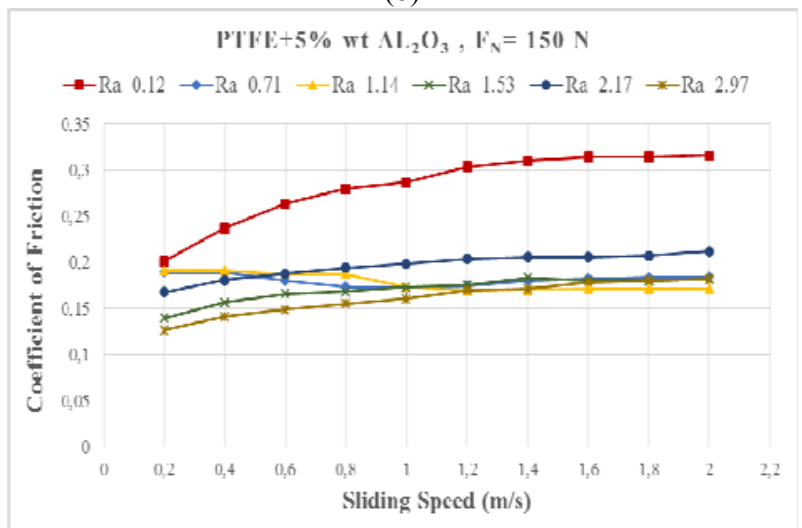

(c)

Fig. 4 Variation of coefficient friction with sliding speed for filled with $5 \%$ wt $\mathrm{Al}_{2} \mathrm{O}_{3}$ PTFE.

speed. As seen from Figs. 3-5, friction coefficients increase as the average surface roughness decrease. Measured friction coefficient values vary between 0.15 and 0.3 depending on surface roughness.

In Fig. 6, effect of normal load on friction coefficient is given. Generally, variation in the magnitude of load does not have significant effect on the coefficient of friction. 


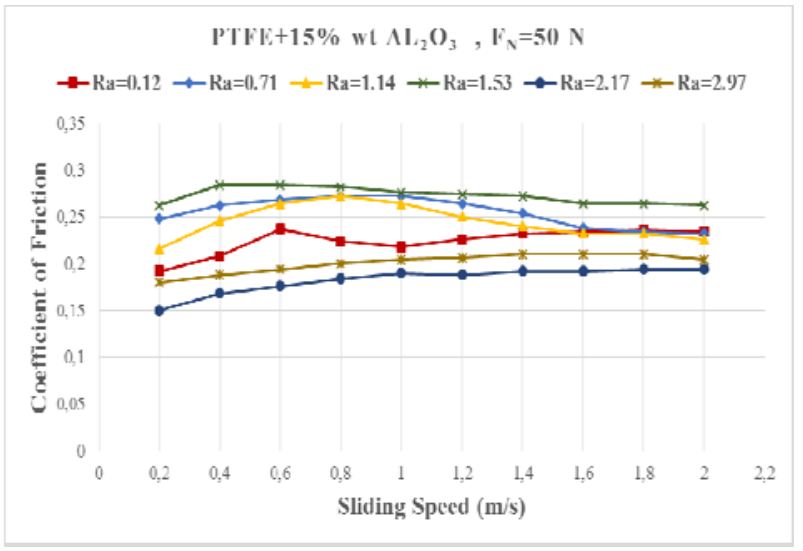

(a)

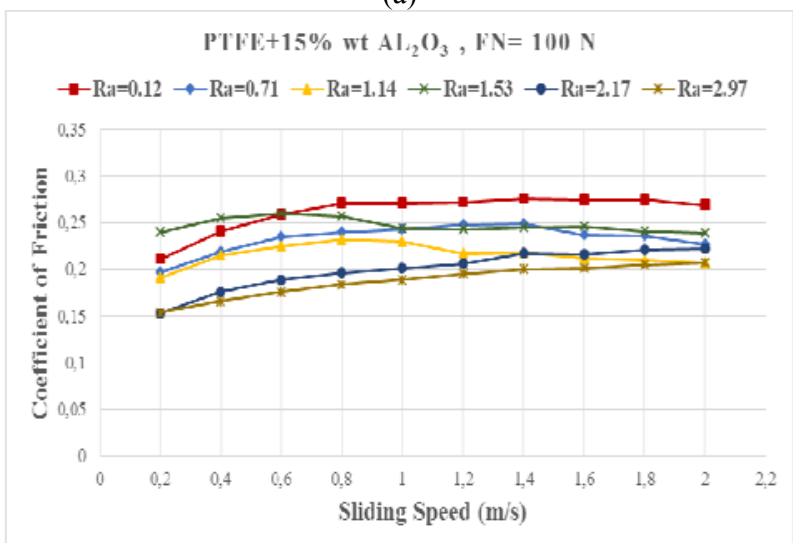

(b)

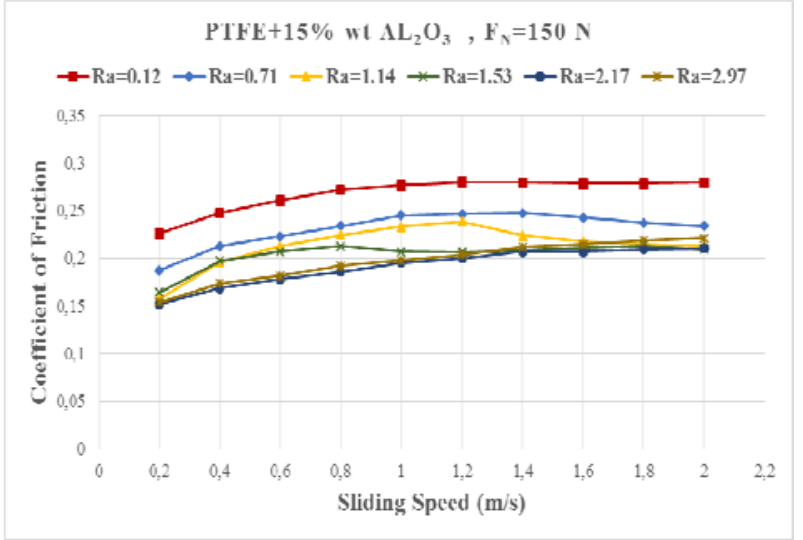

(c)

Fig. 5 Variation of coefficient friction with sliding speed for filled with $15 \%$ wt $\mathrm{Al}_{2} \mathrm{O}_{3}$ PTFE.

Variation of friction coefficient during sliding distance for $100 \mathrm{~N}$ of normal load and $0.6 \mathrm{~m} / \mathrm{s}$ of sliding speed is presented in Fig. 7. In general, values of friction coefficients of filled and unfilled PTFE sliding against counter faces with lower surface roughness remain nearly constant. In the case of higher counter face roughness, slight fluctuations on the

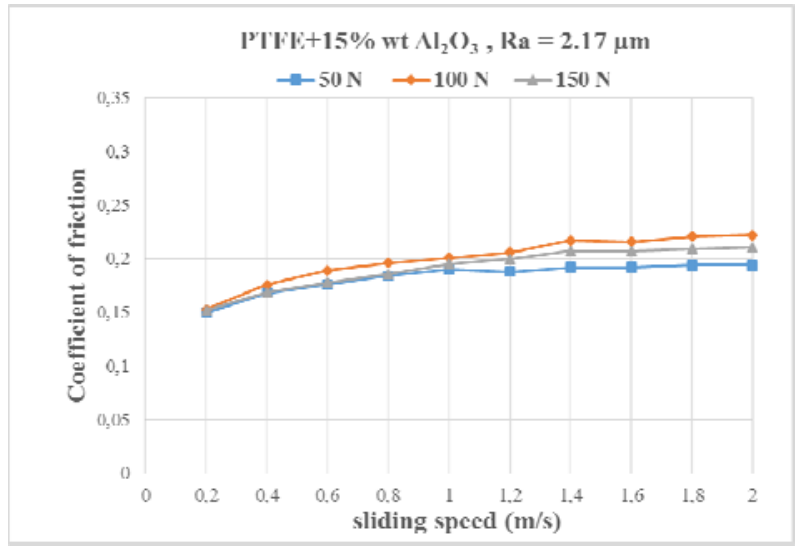

Fig. 6 Variation of coefficient friction with sliding speed for different normal loads.

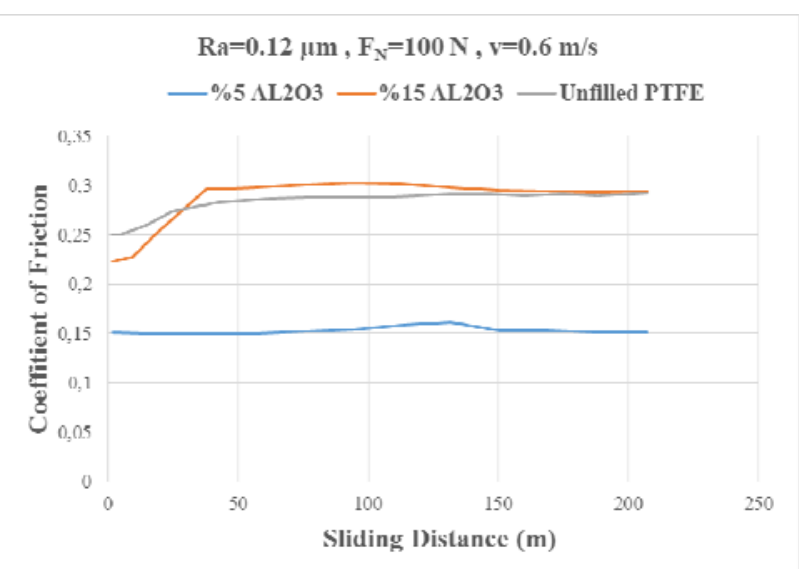

(a)

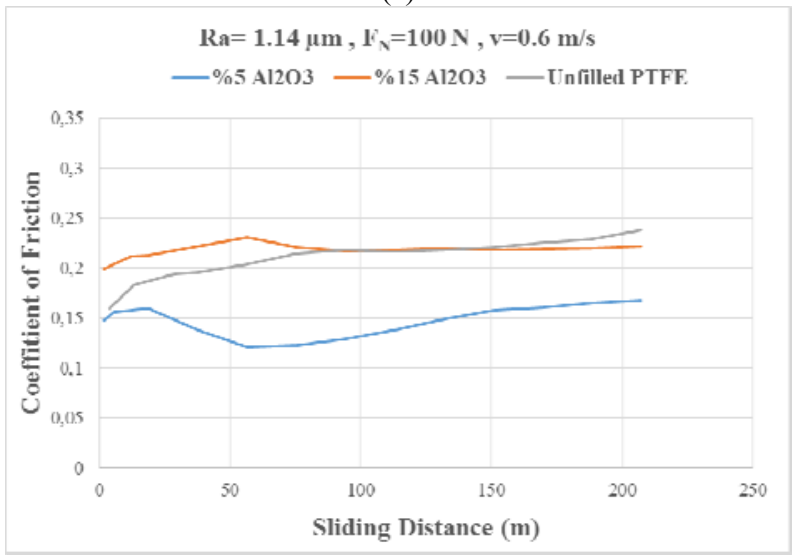

(b)

Fig. 7 Variation of coefficient friction with sliding distance.

friction coefficient values become more remarkable. As seen from the Figs., the lowest friction coefficient value was measured for PTFE filled with $5 \% \mathrm{Al}_{2} \mathrm{O}_{3}$.

In Fig. 8, wear rates of test specimens are given. Unfilled PTFE shows the highest wear rate as expected. Although $5 \% \mathrm{Al}_{2} \mathrm{O}_{3}$ filled PTFE has the lowest 


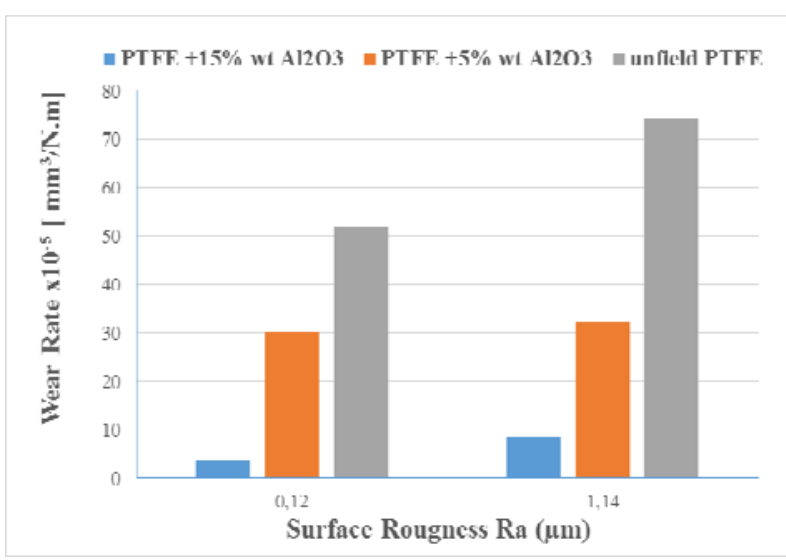

Fig. 8 Wear rates of test specimens.

coefficient of friction, it gives remarkably high wear rate values. The lowest wear rate value was obtained for $15 \% \mathrm{Al}_{2} \mathrm{O}_{3}$ filled PTFE having higher filling ratio.

In Figs. 9 and 10, the optical micrographs of the filled PTFE specimens after wear tests are given for two different surface roughness. As seen from the figures, the wear marks are clearly visible on the direction of motion.

In Fig. 11, the disc surfaces of counter faces are shown for unfilled PTFE (a), filled with $5 \% \mathrm{Al}_{2} \mathrm{O}_{3}$ (b) and $15 \% \mathrm{Al}_{2} \mathrm{O}_{3}$ (c). The discs have been examined to compare the amount of worn particles of polymers on

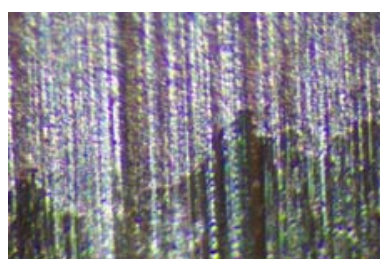

(a)

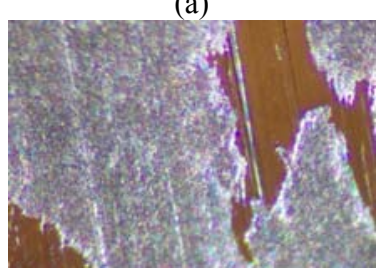

(b)

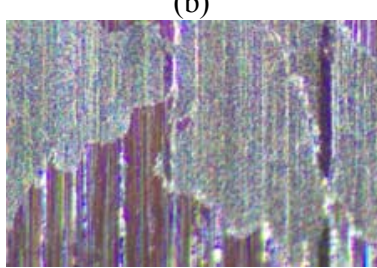

(c)

Fig. 9 Micrographs of (a) unfilled, (b) $5 \%$ wt $\mathrm{Al}_{2} \mathrm{O}_{3}$ and (c) $15 \%$ wt $\mathrm{Al}_{2} \mathrm{O}_{3}$ filled PTFE for $\mathrm{Ra}=0.12 \mu \mathrm{m}(\times 100)$.

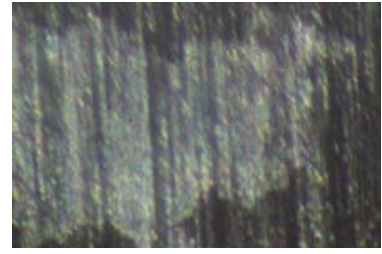

(a)

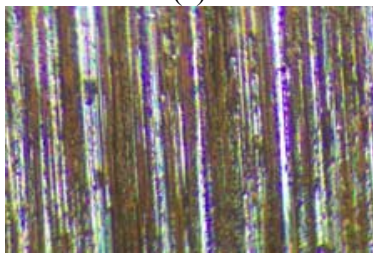

(b)

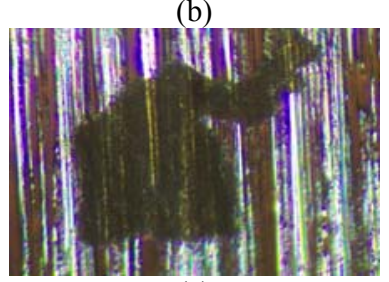

(c)

Fig. 10 Micrographs of (a) unfilled, (b) $5 \%$ wt $\mathrm{Al}_{2} \mathrm{O}_{3}$ and (c) $15 \%$ wt $\mathrm{Al}_{2} \mathrm{O}_{3}$ filled PTFE for $\mathrm{Ra}=1.14 \mu \mathrm{m}(\times 100)$.

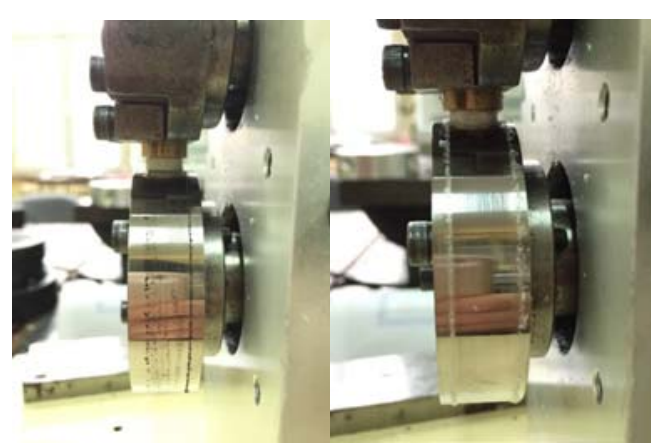

(a)

(b)

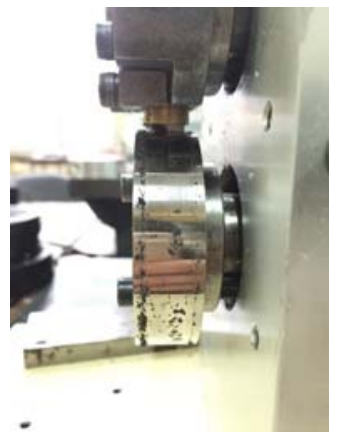

(c)

Fig. 11 Counter-faces after wear tests $(R a=0.12 \mu \mathrm{m})$. (a) Unfilled PTFE, (b) $5 \%$ filled with $\mathrm{Al}_{2} \mathrm{O}_{3}$ and (c) $15 \%$ filled with $\mathrm{Al}_{2} \mathrm{O}_{3}$.

the sliding surfaces. Under these testing conditions, the unfilled samples show thin, millimeter sized, flaky wear debris, which is the indicator of delamination. 


\section{Conclusions}

Regarding all these explanations, the following conclusions can be drawn from the present study:

(1) The lowest coefficient of friction observed for unfilled PTFE at low speeds;

(2) Alumina filled PTFE exhibits a coefficient of friction higher than that of unfilled PTFE. This may be caused by alumina filler has a higher coefficient of friction sliding against steel. As expected, increasing the percentage of the alumina in PTFE increases the hardness and strength of composites, resulting in a decrease of the real contact area of tribo-pairs. Based on adhesion theory of Bowden and Tabor, friction force is proportional to the product of real contact area and effective shear strength. Accordingly, friction force can be found as a multiplication of real contact area and effective shear strength. Thus, PTFE composites exhibit lower coefficient of friction due to the decrease in the real area of contact;

(3) For all specimens, friction coefficient increases with increasing sliding speeds. This result is supported by other works in this topic;

(4) Normal load does not have remarkable effect on coefficient of friction;

(5) Generally, counter-face roughness affects the friction coefficient under constant normal load and sliding speed conditions. Discs with the lower surface roughness have higher coefficient of friction. This can be explained by increase of actual contact area in the case of lower surface roughness;

(6) As expected, adding any filler or reinforcement into PTFE increases its wear resistance considerably. As seen from Fig. 8, increasing filling ratio also has a positive effect on wear resistance;

(7) Increasing surface roughness also increases the wear rate in all polymers. The lowest wear rate is obtained for PTFE $+\% 15 \mathrm{Al}_{2} \mathrm{O}_{3}$ and the highest is obtained for unfilled PTFE.

\section{References}

[1] Goyal, R. K., and Yadav, M. 2014. "The Wear and
Friction Behavior of Novel

Polytetrafluoroethylene/Expanded Graphite

Nanocomposites for Tribology Application." Journal of Tribology 136 (2): 021601-1-5.

[2] McElwain, S. E., Blancheta, T. A., Schadlera, L. S., and Sawyerbet, W. G. 2008. "Effect of Particle Size on the Wear Resistance of Alumina-Filled PTFE Micro- and Nanocomposites.” Tribology Transactions 51: 247-53.

[3] Deli, D., Qunji, X., and Hongli, W. 1989. "Study of the Wear of Filled Polytetrafluoroethylene." Wear 134 (2): 283-95.

[4] Sawyer, W. G., Freudenberg, K. D., Bhimaraj, P., and Schadler, L. S. 2003. "A Study on the Friction and Wear Behavior of PTFE Filled with Alumina Nanoparticles." Wear 254: 573-80.

[5] Burris, D. L., and Sawyer, W. G. 2007. "Polymeric Nanocomposites for Tribological Applications." Wear 262 (1-2): 220-4.

[6] Yuan, X. D., and Yang, X. J. 2010. "A Study on Friction and Wear Properties of PTFE Coatings under Vacuum Conditions." Wear 269 (3-4): 291-7.

[7] Goyal, R. K., Tiwari, A. N., and Negi, Y. S. 2008. "High Performance Nanocomposites for Tribological Applications: Preparation and Characterization." Mater. Sci. Eng. A 486 (1-2): 602-10.

[8] Kulkarni, P. V., and Chapkhhane, N. K. 2012. "Development and Testing of PTFE Based Composite Bearing Material for Turbine Pump." International Journal of Engineering and Advanced Technology 1: 15-20.

[9] Stanković1, M., Vencl, A., and Marinković, A. 2013. "A Review of the Tribological Properties of PTFE Composites Filled with Glass, Graphite, Carbon or Bronze Reinforcement." In Proceedings of SERBIATRIB '13th International Conference on Tribology, 135-40.

[10] Xiang, D., Li, K., and Shu, W. 2007. "On the Tribological Properties of PTFE Filled.” Journal of Reinforced Plastics and Composites 26 (3): 331-9.

[11] Parlar, Z., and Temiz, V. 2004. "Experimental Analysis of Tribological Characteristics of $\mathrm{Al}_{2} \mathrm{O}_{3}$ Filled PTFE Journal Bearings." In Proceedings of 10th Materials Symposium in Denizli, Turkey, 815-23.

[12] Menezes, P. L., Kishore and Kailas, S. V. 2009. "Influence of Surface Texture and Roughness Parameters on Friction and Transfer Layer Formation during Sliding of Aluminum Pin on Steel Plate." Wear 267: 1534-49.

[13] Khedkar, J., Negulescu, I., and Meletis, F. I. 2002. "Sliding Wear Behavior of PTFE Composites." Wear 252: 361-9. 